\title{
Letter to Editor: A Letter About Phenobarbital Poisoning
}

\author{
Zahra Ataee $^{1^{*}}$ Q, Maryam Sayyari Doughabadi² \\ 1. Medical Toxicology Research Center, Faculty of Medicine, Mashhad University of Medical Sciences, Razavi Khorasan, Iran. \\ 2. Emergency Medicine Department, Faculty of Medicine, Mashhad University of Medical Sciences, Razavi Khorasan, Iran.
}

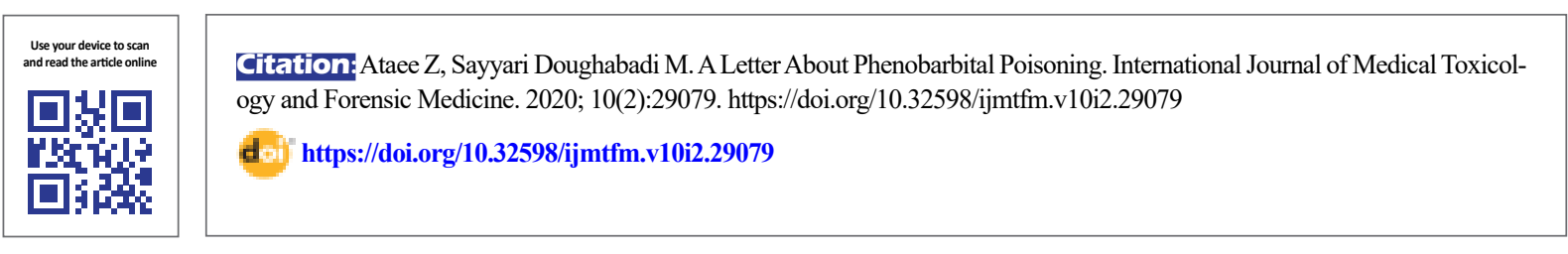

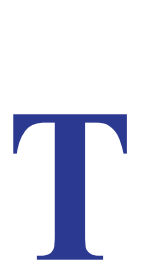

he ever-increasing sensitivity of humans and living in a world full of stress and anxiety have led to the increased consumption of painkillers and sleeping pills. Barbiturates, which are among the most important sedatives, are regularly used by ordinary people. Addiction, suicide, and accidental deaths from inappropriate use of these drugs have been a subject of constant concern in medicine $[1,2]$.

Phenobarbital was the first effective antiepileptic drug introduced in 1912 [3]. It is a barbiturate that slows down the activities of the brain and nervous system and is used as a sedative in the treatment or prevention of seizures and in short-term therapies. Phenobarbital is used in all types of absence epilepsy and continuous epileptic seizures. Injectable phenobarbital is used for the emergency treatment of some acute seizures, including the attacks with eclampsia, meningitis, and toxic reactions to strychnine. It is also used for the prevention and treatment of febrile seizures [4].

Nowadays, phenobarbital is commonly used for seizures, but it is the drug of choice for seizures in children over two months of age. Although phenobarbital has less efficacy than phenytoin or carbamazepine in adults, it is used for the treatment of generalized partial and tonic-clonic epilepsies in all age groups [5].
Phenobarbital mechanism of action is two-fold: it increases the inhibitory effect of gamma-aminobutyric acid, and it reduces the stimulatory effect of glutamic acid, thereby preventing the propagation of waves from the epileptic focus by selective inhibition of abnormal neurons [6].

The most common side effect of phenobarbital is sleepiness and fatigue (decreased consciousness level). Other side effects include depression, hyperactivity in children, concentration problems, confusion, memory problems, reduced libido (in men), stuttering, upset stomach, anemia, folic acid deficiency, rash, fever, declined calcium level, and bone marrow weakness [7].

There are reports of severe poisoning and even death following the overdose of barbiturates, especially phenobarbital worldwide [2-8]. Therefore, given the high frequency of fatal poisonings with phenobarbital, it is necessary to investigate the issue.

The patient mentioned was a 37-year-old woman who was found in the bathroom of her home, with reduced consciousness half an hour before being transported to the hospital. According to the patient's companion, there was a possibility of taking an unknown amount of alprazolam as the pills were available to the patient. It should be noted that she had no history of any diseases or drug use. At the initial examination, the patient was not conscious, had tachypnea, and her heartbeat was 95

* Corresponding Author:

Zahra Ataee, MD.

Address: Medical Toxicology Research Center, Faculty of Medicine, Mashhad University of Medical Sciences, Razavi Khorasan, Iran.

Tel: +98 (915) 3172461

E-mail: ataeez@mums.ac.ir 
per minute. Her BP was $80 / 100 \mathrm{~mm} \mathrm{Hg}$, and the $\mathrm{SpaO}_{2}$ was $95 \%$. The examination of the head and neck showed no significant problem other than the myotonic pupils without responses to light. The patient had low $\mathrm{SpaO}_{2}$ and respiratory rate in the early hours of admission to the emergency room. Because of the impaired blood gasometry, the patient was intubated and underwent mechanical ventilation.

There was no acute abnormality in the initial ECG. The blood glucose was in the normal range, and an emergency brain CT scan was performed, the result of which lacked acute lesions. The disorder in venous blood gas was gradually corrected by mechanical ventilation. Her phenobarbital blood level was $120 \mathrm{mg} / \mathrm{dL}$, confirming the toxic level (normal range: $20-40 \mathrm{mg} / \mathrm{dL}$ ).

Then, the initial and usual treatment of phenobarbital poisoning began. Because of the high level of phenobarbital, dialysis was decided for the patient. However, dialysis was postponed because of her low BP, but it was performed following hemodynamic adjustments. Later on, her phenobarbital blood levels slightly decreased, but the patient's consciousness remained unchanged. Consultation with a neurologist was performed to identify the cause of consciousness decline, and the neurologist expressed the possibility of toxic encephalopathy. After the second dose of dialysis, the patient's breathing recovered spontaneously, and her consciousness increased gradually, she even extubated herself, and her condition continued to improve.

In general, over-administration of phenobarbital can cause coma, cardiovascular collapse, cardiac arrest, hypotonia, hyporeflexia, hypothermia, hypertension, and respiratory problems [9]. In our study, we also observed decreased consciousness and respiratory issues in the patient. Thus, careful monitoring of drug levels is necessary due to the potential severe harm caused by phenobarbital poisoning and the lack of relevant information as well as the limited therapeutic indices.

\section{Ethical Considerations}

\section{Compliance with ethical guidelines}

All ethical principles were considered in this article.

Funding

This study funded by Mashhad University of Medical Sciences.

\section{Author's contributions}

All authors contributed in preparing this article.

\section{Conflict of interest}

The authors declared no conflict of interest.

\section{References}

[1] Bronstein AC, Spyker DA, Cantilena LR Jr, Green JL,Rumack BH, Giffin SL. 2008 Annual report of the American Association of poison control centers' National Poison Data System (NPDS): 26th Annual report. Clin Toxicol (Phila). 2009; 47(10):911-1084. [DOI:10.3109/15563650.2012.746424] [PMID]

[2] Mowry JB, Spyker DA, Cantilena LR Jr, Bailey JE, Ford M. 2012 Annual report of the American association of poison control centers' National Poison Data System (NPDS): 30th Annual report. Clin Toxicol (Phila). 2013; 51(10):949-1229. [D OI:10.3109/15563650.2013.863906] [PMID]

[3] Shadnia S, Amiri H, Hassanian-Moghaddam H, Rezai M, Vasei Z, Ghodrati N, et al. Favorable results after conservative management of 316 valproate intoxicated patients. J Res Med Sci. 2015; 20(7):656-61. [DOI:10.4103/1735-1995.166211] [PMID] [PMCID]

[4] Thuan LQ, Ngoc ND, Due P. Effectiveness of continuous veno-venous hemofiltration and intermittent hemodialysis in the treatment of severe acute phenobarbital poisoning. Asia Pac J Med Toxicol. 2013; 2(1):10-3. http:/ / eprints.mums ac.ir/8205/

[5] Browne TR, Holmes GL. Handbook of epilepsy. Jones \& Bartlett Learning: Massachusetts; 2008.

[6] Mactier R, Laliberté M, Mardini J, Ghannoum M, Lavergne V, Gosselin S, et al. Extracorporeal treatment for barbiturate poisoning: Recommendations from the EXTRIP Workgroup. Am J Kidney Dis. 2014; 64(3):347-58. [DOI:10.1053/j. ajkd.2014.04.031] [PMID]

[7] Ruhe M, Grautoff S, Kähler J, Pohle T. Suicide attempt by means of phenobarbital overdose. Effective treatment with continuous veno-venous hemodialysis. Med Klin Intensivmed Notfmed. 2016; 111(2):141-4. [DOI:10.1007/s00063015-0046-7] [PMID]

[8] Hoyland K, Hoy M, Austin R, Wildman M. Successful use of haemodialysis to treat phenobarbital overdose. BMJ Case Rep. 2013; 2013. pii: bcr2013010011. https://www.ncbi.nlm. nih.gov/pubmed/24265338

[9] Proudfoot A, Krenzelok E, Vale J. Position paper on urine alkalinization. J Toxicol Clin Toxicol. 2004; 42(1):1-26. [DOI:10.1081/CLT-120028740] [PMID] 